\title{
The Association of Lyme Disease With Loss of Sexual Libido and the Role of Urinary Bladder Detrusor Dysfunction
}

\author{
Basant K. Puri' ${ }^{1}$, Mussadiq Shah ${ }^{2}$, Peter O.O. Julu' ${ }^{1,2,3}$, Michele C. Kingston², Jean A. Monro² \\ ${ }^{1}$ Department of Medicine, Imperial College London, London, UK; \\ ${ }^{2}$ Department of Neuroscience, Breakspear Medical Group, Hemel Hempstead, Hertfordshire, UK; \\ ${ }^{3}$ National Rett Center, Frösön, Sweden
}

Purpose: The primary aim was to carry out a pilot study to compare the loss of sexual libido between a group of Lyme disease patients and a group of matched controls. The secondary aim was to evaluate whether loss of libido in Lyme disease patients is associated with urinary bladder detrusor dysfunction.

Methods: A group of 16 serologically positive Lyme disease patients and 18 controls were queried directly about loss of libido.

Results: The 2 groups were matched with respect to age, sex, body mass index, and mean arterial blood pressure. None of the 34 subjects was taking medication that might affect sexual libido or had undergone a previous operative procedure involving the genitourinary tract. Of the 16 Lyme disease patients, 8 (50\%) had no loss of libido, and of the 18 controls, none had loss of libido $(\mathrm{P}<0.001)$. In the Lyme disease patient group, there was no statistically significant relationship between loss of libido and urinary bladder detrusor dysfunction $(\mathrm{P}=0.61)$.

Conclusions: This pilot study suggested an association between Lyme disease and loss of libido. Moreover, this loss of libido did not seem to be associated with urinary bladder detrusor dysfunction. Given these results, we recommend further studies to confirm the association.

Keywords: Sexual libido; Lyme disease; Neurogenic urinary bladder; Urinary bladder

\section{INTRODUCTION}

Urinary bladder detrusor dysfunction is associated with urinary incontinence and significant morbidity, which can affect the social, psychological, occupational, domestic, physical, and sexual lives of affected patients [1]. Furthermore, Yip et al. [2] have reported that, compared with healthy, matched controls, women with detrusor dysfunction or urodynamic stress incontinence have significantly poorer marital relationships and significantly less sexual satisfaction.

Recently, in a systematic controlled study, we confirmed that Lyme disease (borreliosis) is associated with urinary bladder detrusor dysfunction [3]. Furthermore, Kim et al. [4] have re- cently reported on a 32-year-old man with Lyme disease who had symptoms of rapidly progressive bilateral ptosis, dysphagia, spastic paraparesis, and voiding difficulty. Lyme disease is a systemic arthropod-borne zoonosis caused by Borrelia spirochaetes, which can invade the skin causing erythema migrans and problems with the musculoskeletal system (Lyme arthritis), cardiovascular system (Lyme carditis), and nervous system (Lyme neuroborreliosis) [5]. To the best of our knowledge, there are no published studies to date on the relationship between Lyme disease and sexual libido.

Given that Lyme disease is associated with urinary bladder detrusor dysfunction and that the latter is associated with sexual dysfunction and may affect the nervous system, we hypothe-
Corresponding author: Basant K. Puri

Imaging Directorate, Block A, Level 1, Hammersmith Hospital, Du Cane Road, London W12 0HS, UK

Tel: +44-1442-261-333 (ext. 314) / Fax: +44-1442-266-388 /

E-mail: basant.puri@imperial.ac.uk

Submitted: April 29, 2014 / Accepted after revision: June 2, 2014
This is an Open Access article distributed under the terms of the Creative Commons Attribution Non-Commercial License (http://creativecommons.org/licenses/by-nc/3.0/) which permits unrestricted non-commercial use, distribution, and reproduction in any medium, provided the original work is properly cited. 
sized that Lyme disease is associated with reduced sexual libido.

The aim was to test our hypothesis by carrying out the first systematic study to compare loss of sexual libido between a group of Lyme disease patients and a group of matched controls. The secondary aim was to study the relationship between loss of libido and symptoms of urinary bladder detrusor dysfunction.

\section{MATERIALS AND METHODS}

\section{Subjects}

This was a cross-sectional pilot study carried out in the Breakspear neuroscience department. Serologically positive Lyme disease patients, undergoing routine clinical tests, and normal controls were assessed with respect to medication, past medical history, body mass, and arterial blood pressure. Exclusion criteria included medication use that might affect sexual libido: tricyclic antidepressants, selective serotonin reuptake inhibitors, finasteride, antihistamines, (medical) marijuana, antiepileptic medication, opioid medication, and beta-adrenergic antagonists; and medication that might affect urinary bladder function: diuretics, calcium channel blockers, alpha-adrenergic antagonists, antipsychotics, tricyclic antidepressants, selective serotonin reuptake inhibitors, muscle relaxants, opioids, and theophylline. Other exclusions were operative procedures that might affect sexual or urinary bladder function: procedures on the spin, pelvis, or genitourinary tract.

The research ethics committee of our institution approved the study, and we obtained written informed consent from all subjects. Additionally, the study was performed in accordance with the Declaration of Helsinki.

\section{Assessment of Libido and Detrusor Dysfunction Symptoms}

Sexual libido was queried directly for each subject. For male subjects, a reduced desire to engage in sexual intercourse was possibly accompanied by an insufficiently strong erection for

Table 1. Bladder control - detrusor function questions

1. Do you feel your bladder is empty after you have passed urine?

2. Do you have difficulty starting to pass urine?

3. Can you pass or hold urine when you want to?

4. How often do you empty your bladder during the daytime?

5. How often do you empty your bladder at night? penetrative sexual intercourse or a noticeably reduced duration of penile erection associated with sexual stimulation. We assessed detrusor function as described in our previous study [3] using the survey shown in Table 1. Subjects answering in the affirmative to questions 1 to 3 , or 5 (consistent with nocturia) were considered to be symptomatic of detrusor dysfunction.

\section{Statistical Analysis}

For the Lyme disease and control groups, normal, continuous variables that did not have significantly different variances were compared using independent samples t-tests (equal variances). Discrete nominal variables were compared using Fisher exact probability test. All tests were two-tailed. The software packages used for the statistical analyses were R ver. 2.15.0 (R Foundation for Statistical Computing, Vienna, Austria) and IBM SPSS ver. 21.0 (IBM Co., Armonk, NY, USA).

\section{RESULTS}

A total of 34 subjects were studied: 16 (6 male) serologically positive Lyme disease patients and 18 (7 male) control subjects. The 2 groups were matched according to mean age, sex, mean body mass index, and mean arterial blood pressure (Table 2).

Of 16 patients with Lyme disease, 8 (50\%) had a loss of sexual libido versus none of the controls (Fisher exact probability test, $\mathrm{P}=0.0007)$. Urinary bladder detrusor function data were available for 15 Lyme disease patients. Of the 8 subjects with reduced libido, 2 (25\%) had urinary bladder detrusor dysfunction, and of the remaining 7 without reduced libido, 3 (43\%) had urinary bladder detrusor dysfunction (Fisher exact probability test, $\mathrm{P}=0.608)$.

Table 2. The mean age, sex ratio, mean body mass and mean arterial blood pressure for each group; standard errors are given in parentheses

\begin{tabular}{lccc}
\hline Variable & $\begin{array}{c}\text { Lyme disease } \\
(\mathrm{n}=16)\end{array}$ & $\begin{array}{c}\text { Controls } \\
(\mathrm{n}=18)\end{array}$ & P-value \\
\hline Age $(\mathrm{yr})$ & $36.0 \pm 4.1$ & $44.7 \pm 3.9$ & 0.134 \\
Sex & & & 1.000 \\
Male & 6 & 7 & \\
Female & 10 & 11 & \\
Body mass index $\left(\mathrm{kg} / \mathrm{m}^{2}\right)$ & $25.2 \pm 1.4$ & $24.6 \pm 0.8$ & 0.694 \\
Arterial blood pressure $(\mathrm{mm} \mathrm{Hg})$ & $74.0 \pm 4.4$ & $66.9 \pm 4.4$ & 0.263 \\
\hline
\end{tabular}

Values are presented as mean \pm standard error. 


\section{DISCUSSION}

This pilot study suggests an association between Lyme disease and loss of sexual libido, in the small sample studied. There was insufficient evidence to suggest that this loss of libido was a consequence of urinary bladder detrusor dysfunction.

Lower urinary tract symptoms (LUTS) other than daytime urinary incontinence (questions 1, 2, 3, and 5 in Table 1) were adopted as parameters for detrusor muscle dysfunction in this study. It should be noted that, in general, the degree of impact of urinary incontinence on sexual function may not be similar to that of other LUTS.

This is the first study concerning loss of libido in patients with Lyme disease. The high percentage of Lyme disease patients with loss of libido in this study, coupled with the increasing incidence of the disease in the geographical spread of infected arthropods [3], points to the need for further, larger studies of sexual dysfunction that might be caused by this infectious disease. It would be appropriate for such studies to include a well-validated tool with which to assess libido more comprehensively, such as the International Index of Erectile Function-5 questionnaire for male subjects.

\section{CONFLICT OF INTEREST}

No potential conflict of interest relevant to this article was reported.

\section{REFERENCES}

1. Kelleher CJ, Cardozo LD, Khullar V, Salvatore S. A new questionnaire to assess the quality of life of urinary incontinent women. $\mathrm{Br} J$ Obstet Gynaecol 1997;104:1374-9.

2. Yip SK, Chan A, Pang S, Leung P, Tang C, Shek D, et al. The impact of urodynamic stress incontinence and detrusor overactivity on marital relationship and sexual function. Am J Obstet Gynecol 2003; 188:1244-8.

3. Puri BK, Shah M, Julu PO, Kingston MC, Monro JA. Urinary bladder detrusor dysfunction symptoms in Lyme disease. Int Neurourol J 2013;17:127-9.

4. Kim MH, Kim WC, Park DS. Neurogenic bladder in Lyme disease. Int Neurourol J 2012;16:201-4.

5. Biesiada G, Czepiel J, Leśniak MR, Garlicki A, Mach T. Lyme disease: review. Arch Med Sci 2012;8:978-82. 